\title{
Follow-up results of brain metastasis patients undergoing repeat Gamma Knife radiosurgery
}

\author{
Takao Koiso, MD, ${ }^{1,2}$ Masaaki Yamamoto, MD, PhD, ${ }^{1,3}$ Takuya Kawabe, MD, PhD, ${ }^{4}$ \\ Shinya Watanabe, MD, PhD, ${ }^{5}$ Yasunori Sato, PhD, ${ }^{6}$ Yoshinori Higuchi, MD, PhD, ${ }^{7}$ \\ Tetsuya Yamamoto, MD, PhD, ${ }^{2}$ Akira Matsumura, MD, PhD, ${ }^{2}$ and Hidetoshi Kasuya, MD, $\mathrm{PhD}^{3}$
}

\begin{abstract}
${ }^{1}$ Katsuta Hospital Mito GammaHouse, Hitachinaka; ${ }^{2}$ Department of Neurosurgery, Faculty of Medicine, University of Tsukuba; ${ }^{3}$ Department of Neurosurgery, Tokyo Women's Medical University Medical Center East, Tokyo; 'Department of Neurosurgery, Kyoto Prefectural University of Medicine Graduate School of Medical Sciences, Kyoto; ${ }^{5}$ Department of Neurosurgery, National Hospital Organization Mito Medical Center, Mito; and ${ }^{6} \mathrm{Clinical}$ Research Center and ${ }^{7}$ Department of Neurological Surgery, Chiba University Graduate School of Medicine, Chiba, Japan
\end{abstract}

OBJECTIVE Stereotactic radiosurgery (SRS) without upfront whole-brain radiotherapy (WBRT) has influenced recent treatment recommendations for brain metastasis patients. However, in brain metastasis patients who undergo SRS alone, new brain metastases inevitably appear with relatively high incidences during post-SRS follow-up. However, little is known about the second SRS results. The treatment results of second SRS were retrospectively reviewed, mainly for newly developed or, uncommonly, for recurrent brain metastases in order to reappraise the efficacy of this treatment strategy with a special focus on the maintenance of neurological status and safety.

METHODS This was an institutional review board-approved, retrospective cohort study that used a prospectively accumulated database, including 3102 consecutive patients with brain metastases who underwent SRS between July 1998 and June 2015. Among these 3102 patients, 859 (376 female patients; median age 64 years; range 21-88 years) who underwent a second SRS without WBRT were studied with a focus on overall survival, neurological death, neurological deterioration, local recurrence, salvage SRS, and SRS-induced complications after the second SRS. Before the second SRS, the authors also investigated the clinical factors and radiosurgical parameters likely to influence these clinical outcomes. For the statistical analysis, the standard Kaplan-Meier method was used to determine post-second SRS survival and neurological death. A competing risk analysis was applied to estimate post-second SRS cumulative incidences of local recurrence, neurological deterioration, salvage SRS, and SRS-induced complications.

RESULTS The post-second SRS median survival time was 7.4 months (95\% Cl 7.0-8.2 months). The actuarial survival rates were $58.2 \%$ and $34.7 \%$ at 6 and 12 months after the second SRS, respectively. Among 789 deceased patients, the causes of death could not be determined in 24 patients, but were confirmed in the remaining 765 patients to be nonbrain diseases in 654 (85.5\%) patients and brain diseases in 111 (14.5\%) patients. The actuarial neurological death-free survival rates were $94.4 \%$ and $86.6 \%$ at 6 and 12 months following the second SRS. Multivariable analysis revealed female sex, Karnofsky Performance Scale score of $80 \%$ or greater, better modified recursive partitioning analysis class, smaller tumor numbers, and higher peripheral dose to be significant predictive factors for longer survival. The cumulative incidences of local recurrence were $11.2 \%$ and $14.9 \%$ at 12 and 24 months after the second SRS. The crude incidence of neurological deterioration was $7.1 \%$, and the respective cumulative incidences were $4.5 \%, 5.8 \%, 6.7 \%, 7.2 \%$, and $7.5 \%$ at $12,24,36,48$, and 60 months after the second SRS. SRS-induced complications occurred in 25 patients $(2.9 \%)$ after a median post-second SRS period of 16.8 months (range 0.6-95.0 months; interquartile range 5.6-29.3 months). The cumulative incidences of complications were $1.4 \%, 2.0 \%, 2.4 \%, 3.0 \%$, and $3.0 \%$ at $12,24,36,48$, and 60 months after the second SRS, respectively.

CONCLUSIONS Carefully selected patients with recurrent tumors-either new or locally recurrent-are favorable candidates for a second SRS, particularly in terms of neurological status maintenance and the safety of this treatment strategy.

http://thejns.org/doi/abs/10.3171/2016.6.GKS161404

KEY WORDS brain metastases; radiosurgery; Gamma Knife; re-treatment; oncology; stereotactic radiosurgery

ABBREVIATIONS HR = hazard ratio; IQR = interquartile range; KPS = Karnofsky Performance Scale; M-RPA = modified recursive partitioning analysis; MST = median survival time; RTOG = Radiation Therapy Oncology Group; SRS = stereotactic radiosurgery; WBRT = whole-brain radiotherapy.

SUBMITTED June 6, 2016. ACCEPTED June 29, 2016.

INCLUDE WHEN CITING DOI: 10.3171/2016.6.GKS161404. 
$\mathrm{D}$ UE to prognostic improvements in cancer patients, mainly due to recent advances in systemic cancer treatment, recent estimates suggest that the number of patients with brain metastases has been gradually rising. ${ }^{13,18,32}$ Stereotactic radiosurgery (SRS) has influenced recent treatment recommendations for brain metastasis patients, although whole-brain radiotherapy (WBRT) has long been the standard treatment for brain metastases. ${ }^{4,12,27,28}$ The primary argument against WBRT stems from the risk of deterioration of neurocognitive function, which cannot be ignored in long-surviving patients. ${ }^{1,5} \mathrm{Sec}-$ ond, because WBRT is generally considered to be unrepeatable, the availability of an alternative treatment for brain metastases allows WBRT to be reserved for subsequent treatment attempts, i.e., in cases with meningeal dissemination or miliary metastases for which only WBRT is effective. SRS has overcome several of these limitations, and therefore an increasing number of patients with brain metastases have recently been treated with SRS alone. .,23,35 $^{2}$

In brain metastasis patients who undergo SRS alone, new brain metastases inevitably appear with relatively high incidences during post-SRS follow-up. Using highperformance MR imaging, Hanssens et al. reported that new tumors were diagnosed in $40 \%$ of 835 brain metastasis patients who had undergone SRS alone. ${ }^{11}$ Recently published retrospective and prospective studies based on more than 1000 brain metastasis patients treated with SRS alone disclosed that re-SRS for new tumors was required in $22 \%$ to $34 \%$ of all cases..$^{16,30,31,43,46}$ Several retrospective studies, which were based on relatively small patient numbers, have documented re-SRS to be safe and effective. ${ }^{7,20,32,47}$ However, no follow-up results based on large numbers of brain metastasis patients undergoing second SRS have yet been published. Herein, we retrospectively reviewed the medical records of patients who underwent second SRS mainly for newly developed or, uncommonly, for recurrent brain metastases in order to reappraise efficacy, with a special focus on neurological status maintenance and the safety of this treatment strategy.

\section{Methods \\ Patient Population}

All data collection was performed under an institutional review board-approved retrospective review. The data set consisted of 3102 consecutive brain metastasis patients who were treated with Gamma Knife SRS during the 17-year period between July 1998 and June 2015. After excluding 156 patients who had undergone WBRT before the first SRS, 895 patients who received a second SRS were identified. For a new brain metastasis that developed after the second SRS, our approach was similar to that used for patients with an initially diagnosed brain metastasis. Basically, instead of immediately performing the second SRS, we conducted meticulous follow-up MRI for any new lesions with a diameter of less than 1 $\mathrm{cm}$. However, if the new lesions were located in a critical or eloquent area, like the brainstem, optic apparatus, or motor area, we performed the second SRS without further observation even if the maximum lesion diameter was smaller than $1 \mathrm{~cm}$. After 36 patients who had under- gone WBRT after the first SRS procedure were excluded from the study, 859 patients remained for analysis (680 [79.2\%] patients with new tumors, 83 [9.7\%] patients with local recurrence of irradiated tumors, and 96 [11.2\%] patients with both). The median interval between the first and second procedures was 6.4 months (range 0.5-74.4 months; interquartile range [IQR] 4.3-10.4 months). Because all patients were referred to our institution by their primary physicians, the decision as to whether SRS could be performed was made by the second author (M.Y.). We fundamentally did not perform SRS on patients with low Karnofsky Performance Scale (KPS) scores because of systemic diseases, a noncooperative state due to poor neurocognitive function, meningeal dissemination, and/or an expected survival period of 3 months or less. The characteristics of the pre-second SRS cases are shown in Table 1, along with characteristics noted before the first SRS. Because all patients had been referred to our institution, as previously mentioned, the primary physicians had already made the decision as to whether to perform surgery for brain metastases. For this reason, $196(22.8 \%)$ of the 859 patients had undergone surgery before the first SRS.

The treatment strategies were explained in detail to each patient, as well as at least 1 adult relative, and written informed consent was obtained from all patients by the second author (M.Y.) before both the first and second SRS procedures were performed. Because our previous report described our radiosurgical techniques in detail, they are not repeated herein. ${ }^{40,43}$ Briefly, SRS was performed using a Leksell Gamma Knife Model B unit (1998e2003; Elekta Instruments AB) before June 2003, a Leksell Gamma Knife Model C unit (Elekta Instruments $\mathrm{AB}$ ) after June 2003 but before December 2013, or a Leksell Perfexion unit (Elekta Instruments AB) thereafter.

\section{Clinical Outcomes}

The post-second SRS primary end point was overall survival, and the post-second SRS secondary end points were neurological death, neurological deterioration, local recurrence of the treated tumor at the time of the second SRS, irradiation-induced major complications, and further salvage SRS for new or recurrent lesions. For each end point, failures were regarded as events and any other end points were censored. The overall survival time was defined as the interval between the second SRS and death due to any cause (e.g., progression of systemic metastases and/or brain metastases, other disease unrelated to cancer, accident, suicide) or the day of the last follow-up. Neurological death was defined as death caused by any intracranial disease, including tumor recurrence, carcinomatous meningitis, cerebral dissemination, and progression of other untreated intracranial tumors. The local recurrencefree survival time was defined as the interval between the second SRS and the day when the follow-up MRI demonstrated local recurrence (at the irradiated lesion at the time of the second SRS). Basically, local recurrence was detected by MRI (regression of the enhanced area on T1weighted imaging after contrast agent administration and an enlarged tumor core on T2-weighted MR imaging). ${ }^{15}$ However, because it is difficult to distinguish recurrence from necrosis, we needed to perform ${ }^{11} \mathrm{C}$-methionine 
TABLE 1. Summary of pre-first and pre-second SRS demographic characteristics*

\begin{tabular}{|c|c|c|}
\hline Characteristic & Pre-1st SRS & Pre-2nd SRS \\
\hline No. of patients & 3102 & 859 \\
\hline \multicolumn{3}{|l|}{ Age, yrs } \\
\hline Mean & 66 & 64 \\
\hline Range & $19-96$ & $21-88$ \\
\hline IQR & $57-73$ & $56-71$ \\
\hline \multicolumn{3}{|l|}{ Sex } \\
\hline Male & $1842(59.4)$ & $483(56.2)$ \\
\hline Female & $1260(40.6)$ & $376(43.8)$ \\
\hline \multicolumn{3}{|l|}{ Neurological symptom } \\
\hline Yes & $1601(51.6)$ & $404(47.0)$ \\
\hline No & $1501(48.4)$ & $455(53.0)$ \\
\hline \multicolumn{3}{|l|}{ Primary cancer status } \\
\hline Controlled & $1028(33.1)$ & $390(45.4)$ \\
\hline Uncontrolled & $2074(66.9)$ & $469(54.6)$ \\
\hline \multicolumn{3}{|l|}{ KPS score } \\
\hline$\geq 80 \%$ & $2379(76.7)$ & $727(84.6)$ \\
\hline$\leq 70 \%$ & $723(23.3)$ & $132(15.4)$ \\
\hline \multicolumn{3}{|l|}{ M-RPA class $†$} \\
\hline $1+2 a$ & $712(23.0)$ & $225(27.4)$ \\
\hline $2 b$ & $951(30.7)$ & $310(37.7)$ \\
\hline $2 c+3$ & $1439(46.4)$ & $287(34.9)$ \\
\hline \multicolumn{3}{|l|}{ Primary cancer } \\
\hline Non-small cell lung cancer & $1711(55.2)$ & $487(56.7)$ \\
\hline Small cell lung cancer & $292(9.4)$ & $77(9.0)$ \\
\hline Breast & $358(11.5)$ & $117(13.6)$ \\
\hline Gastrointestinal tract & $359(11.6)$ & $89(10.4)$ \\
\hline Kidney & $123(4.0)$ & $34(4.0)$ \\
\hline Other & 259 (8.3) & $55(6.4)$ \\
\hline \multicolumn{3}{|l|}{ Prior surgery } \\
\hline Yes & $570(18.4)$ & $196(22.8)$ \\
\hline No & 2532 (81.6) & $663(77.2)$ \\
\hline \multicolumn{3}{|l|}{ Presentation } \\
\hline Synchronous & $531(17.1)$ & $147(17.1)$ \\
\hline Metachronous & 2571 (82.9) & $712(82.9)$ \\
\hline \multicolumn{3}{|l|}{ No. of tumors } \\
\hline Median & 3 & 4 \\
\hline Range & $1-89$ & $1-48$ \\
\hline IQR & $1-8$ & $2-10$ \\
\hline \multicolumn{3}{|l|}{ Tumor vol, $\mathrm{cm}^{3}$} \\
\hline \multicolumn{3}{|l|}{ Cumulative } \\
\hline Median & 5.5 & 2.13 \\
\hline Range & $0.01-126.2$ & $0.02-64.1$ \\
\hline IQR & $1.86-12.95$ & $0.70-5.81$ \\
\hline \multicolumn{3}{|l|}{ Largest tumor } \\
\hline Median & 3.70 & 1.14 \\
\hline Range & $0.01-94.2$ & $0.01-45.26$ \\
\hline IQR & $1.10-8.82$ & $0.35-3.50$ \\
\hline
\end{tabular}

CONTINUED IN NEXT COLUMN »
» CONTINUED FROM PREVIOUS COLUMN

TABLE 1. Summary of pre-first and pre-second SRS demographic characteristics*

\begin{tabular}{lcc}
\hline \multicolumn{1}{c}{ Characteristic } & Pre-1st SRS & Pre-2nd SRS \\
\hline Peripheral dose (Gy) & & \\
\hline Median & 21.0 & 24.0 \\
\hline Range & $5.8-32.0$ & $10.0-25.0$ \\
\hline IQR & $20.0-24.0$ & $20.0-24.0$ \\
\hline Maximum dose (Gy) & \\
\hline Median & 35 & 32.0 \\
\hline Range & $15.0-60.0$ & $3.8-50.0$ \\
\hline IQR & $30.0-40.0$ & $30.0-40.0$ \\
\hline Mos btwn 1st \& 2nd SRS & & \\
\hline Median & & 6.4 \\
\hline Range & & $0.5-74.4$ \\
\hline IQR & & $4.2-10.5$ \\
\hline
\end{tabular}

* Values are presented as the number of patients (\%) unless otherwise indicated.

$†$ Refer to the studies by Yamamoto et al. ${ }^{44,45}$

PET on 71 cases in order to make an accurate determination..$^{22,37,41}$ Thus, all findings of recurrence on MRI and/or PET were regarded as events and any other findings were censored.

Also, the third SRS-free survival time was analyzed based on the interval between the second SRS and the day that the third SRS was performed; all repeat SRS procedures for such lesions were regarded as events and any other procedures were censored.

The neurological deterioration-free survival time was defined as the interval between the second SRS and the day when any brain disease causing neurological worsening manifested (i.e., local recurrence, progression of new lesions, and SRS-induced complications). Decreases in the KPS scores in patients with scores of $20 \%$ or less due to neurological worsening were regarded as events and any others as censored. Patients with major complications included those with Radiation Therapy Oncology Group (RTOG) neurotoxicity of Grade 2 or worse and, even if the grade was either 0 or 1 , those in whom surgical intervention was required based on sequential MRI follow-up that demonstrated progressive enlargement of a cyst and/ or a mass lesion that made further observation excessively high risk. All of these conditions were regarded as events and any other events were censored. ${ }^{29}$

\section{Statistical Analysis}

All data were analyzed according to the intention-totreat principle. For the baseline variables, summary statistics were constructed using frequencies and proportions for categorical data and the medians, IQRs, and ranges for continuous variables. The standard Kaplan-Meier method was used to analyze the overall and neurological deathfree survival periods. Also, univariate and multivariate analyses using Cox proportional hazard modeling were performed to determine the pre-second SRS clinical factors that favor longer survival. 
TABLE 2. Crude incidences of various treatment results after the first and second SRS procedures*

\begin{tabular}{lcc}
\hline \multicolumn{1}{c}{ Variable } & $\begin{array}{c}\text { Post-1st SRS } \\
(\mathrm{n}=3098)\end{array}$ & $\begin{array}{c}\text { Post-2nd SRS } \\
(\mathrm{n}=859)\end{array}$ \\
\hline Neurological death $\dagger$ & $313(11.0)$ & $111(14.5)$ \\
\hline Neurological deterioration & $382(12.3)$ & $61(7.1)$ \\
\hline Local recurrence & $180(8.0)$ & $90(15.8)$ \\
\hline Salvage SRS & $935(30.2)$ & $281(32.7)$ \\
\hline Salvage WBRT & $108(3.5)$ & $28(3.3)$ \\
\hline Salvage surgery & $43(1.4)$ & $16(1.9)$ \\
\hline SRS-related complications & $88(2.8)$ & $25(2.9)$ \\
\hline
\end{tabular}

* Values are presented as the number of patients (\%).

† Based on 2721 (first SRS) and 765 (second SRS) deceased patients whose causes of death were determined (112 patients in first SRS group and 24 patients in second SRS group were excluded because the causes of death were unavailable).

‡ Based on 2243 (first SRS) and 571 (second SRS) patients (859 patients in the first SRS group and 288 patients in second SRS group were excluded because the neuroimaging results were unavailable).

For time-to-event outcome analyses of the 4 aforementioned end points, a competing risk analysis was applied because death is a competing risk for these end points. The standard Kaplan-Meier method was applied, i.e., follow-up of a patient who developed a competing event (e.g., death) was simply censored. We considered the competing risk analysis to have been necessary, as in our prior studies, for evaluation of these data. Also, to identify the baseline and clinical variables associated with the 4 aforementioned outcomes, competing risk analyses were performed with the Fine-Gray generalization of the proportional hazards model to account for death as a competing risk. Fine-Gray generalization makes use of the subdistribution hazard to model cumulative incidence, thereby quantifying the overall benefit or harm of an exposure.

All comparisons were planned, and the tests were 2-sided. A $p$ value $<0.05$ was considered to be statistically significant. All statistical analyses were performed by a statistician (Y.S.) using SAS software (version 9.4; SAS Institute) and the R statistical program (version 3.10). Before performing the statistical analyses, the database was cleaned by one of the coauthors (Y.H.). These 2 authors were not involved in either SRS treatment or patient follow-up.

\section{Results}

The median follow-up time among the 70 censored observations was 10.3 months (IQR 2.2-35.9 months; maximum 147.2 months) after the second SRS; 789 patients (91.9\%) had died as of the end of March 2016. The causes of death could not be determined in 24 patients, but were confirmed in the remaining 765 patients to be nonbrain diseases in $654(85.5 \%)$ patients and brain diseases in 111 $(14.5 \%$ ) patients (Table 2). As shown in Fig. 1A, the overall median survival time (MST) after the second SRS was 7.4 months (95\% CI 7.0-8.2 months). The actuarial survival rates were $58.2 \%, 34.7 \%, 23.0 \%, 15.6 \%, 9.1 \%$, and $4.3 \%$ at $6,12,18,24,36$, and 60 months, respectively, after the second SRS. As shown in Table 3, the multivariable analy-

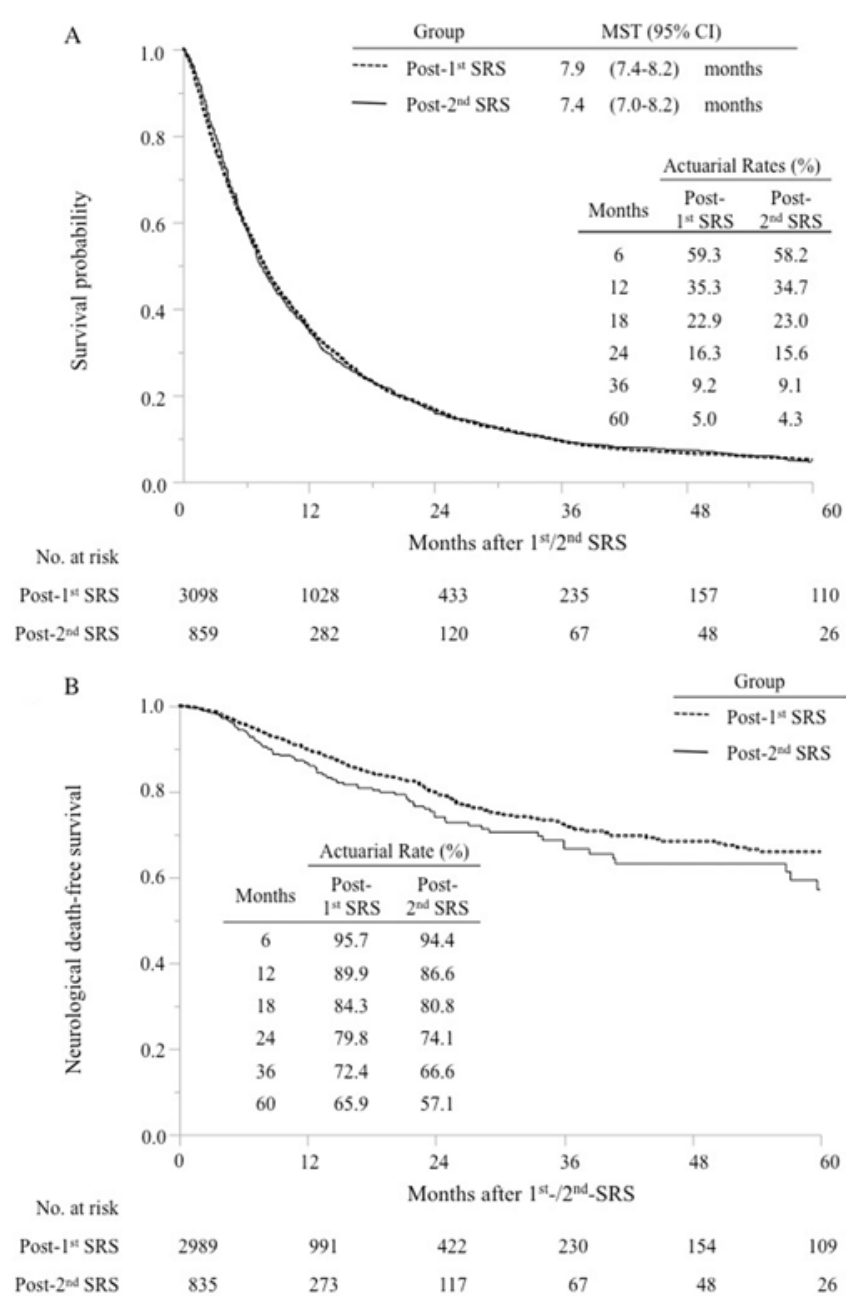

FIG. 1. Survival probability (A) and neurological death-free survival (B) after the first (dotted line) and second (solid line) SRSs, as estimated using the standard Kaplan-Meier method.

sis revealed female sex (hazard ratio [HR] 1.423; 95\% CI $1.233-1.644 ; \mathrm{p}<0.0001$ ), KPS score $80 \%$ or better (HR 1.753; 95\% CI 1.410-2.167; $\mathrm{p}<0.0001)$, better modified recursive partitioning analysis (M-RPA) class ( $2 \mathrm{~b}$ vs $1+2 \mathrm{a}$ : HR $1.483 ; 95 \%$ CI $1.220-1.807$; $p<0.0001)(2 c+3$ vs $2 b$; HR 1.353; 95\% CI 1.133-1.613; $p=0.0008$ ), a smaller number of tumors ( 5 or more vs 4 or fewer: HR $1.404 ; 95 \%$ CI $1.190-1.657 ; \mathrm{p}<0.0001)$, and a peripheral dose of $24 \mathrm{~Gy}$ or more (HR 1.376; 95\% CI 1.172-1.612; $\mathrm{p}=0.0001$ ) to be significant predictive factors of longer post-second SRS survival. Figure 1B shows neurological death-free survival. The actuarial neurological death-free survival rates were $94.4 \%, 86.6 \%, 80.8 \%, 74.1 \%, 66.6 \%$, and $57.1 \%$ at 6 , $12,18,24,36$, and 60 months, respectively, after the second SRS. As shown in Tables 2 and 4, the crude incidence of neurological deterioration was $7.1 \%$ and the cumulative incidences were $4.5 \%, 5.8 \%, 6.7 \%, 7.2 \%$, and $7.5 \%$ at 12 , $24,36,48$, and 60 months, respectively, after the 2nd SRS.

Post-second SRS neuroimaging examinations were available in 571 patients. In the remaining 288 patients, post-second SRS neuroimaging examinations could not be performed due to early death or deterioration of the 
TABLE 3. Univariable and multivariable analyses of survival after the second SRS

\begin{tabular}{|c|c|c|c|c|}
\hline \multirow[b]{2}{*}{ Variable } & \multicolumn{2}{|c|}{ Univariable } & \multicolumn{2}{|c|}{ Multivariable } \\
\hline & $\mathrm{HR}(95 \% \mathrm{Cl})$ & p Value & $\mathrm{HR}(95 \% \mathrm{Cl})$ & p Value \\
\hline \multicolumn{5}{|l|}{ Age, yrs } \\
\hline$\geq 65$ vs $<65$ & $1.038(0.902-1.194)$ & 0.6045 & & \\
\hline \multicolumn{5}{|l|}{ Sex } \\
\hline Male vs female & $1.291(1.121-1.487)$ & 0.0004 & $1.423(1.233-1.644)$ & $<0.0001$ \\
\hline \multicolumn{5}{|l|}{ KPS score } \\
\hline$<80 \%$ vs $\geq 80 \%$ & $2.237(1.838-2.703)$ & $<0.0001$ & $1.753(1.410-2.167)$ & $<0.0001$ \\
\hline \multicolumn{5}{|l|}{ M-RPA } \\
\hline $2 \mathrm{~b}$ vs $1+2 a$ & $1.700(1.421-2.039)$ & $<0.0001$ & $1.483(1.220-1.807)$ & $<0.0001$ \\
\hline $2 c+3$ vs $2 b$ & $1.622(1.375-1.913)$ & $<0.0001$ & $1.353(1.133-1.613)$ & 0.0008 \\
\hline \multicolumn{5}{|l|}{ Original tumor site } \\
\hline Lung vs non-lung & $1.065(0.919-1.238)$ & 0.4031 & & \\
\hline \multicolumn{5}{|l|}{ No. of lesions } \\
\hline$\geq 2$ vs 1 & $1.793(1.510-2.143)$ & $<0.0001$ & $1.239(0.989-1.558)$ & 0.0626 \\
\hline$\geq 5$ vs $\leq 4$ & $1.689(1.463-1.949)$ & $<0.0001$ & $1.404(1.190-1.657)$ & $<0.0001$ \\
\hline \multicolumn{5}{|l|}{ Tumor volume, $\mathrm{cm}^{3}$} \\
\hline Cumulative: $\geq 10$ vs $<10$ & $1.561(1.281-1.887)$ & $<0.0001$ & $1.076(0.787-1.441)$ & 0.6356 \\
\hline Largest tumor: $\geq 10$ vs $<10$ & $1.609(1.256-2.029)$ & 0.0003 & $1.370(0.940-2.012)$ & 0.1014 \\
\hline \multicolumn{5}{|l|}{ Type of recurrence } \\
\hline Remote vs local & $1.291(1.020-1.659)$ & 0.0332 & $1.294(0.976-1.734)$ & 0.0737 \\
\hline Both vs local & $1.644(1.204-2.251)$ & 0.0018 & $1.379(0.974-1.959)$ & 0.0702 \\
\hline \multicolumn{5}{|l|}{ Minimum dose, Gy } \\
\hline$<24$ vs $\geq 24$ & $1.398(1.213-1.609)$ & $<0.0001$ & $1.376(1.172-1.612)$ & 0.0001 \\
\hline
\end{tabular}

patient's general condition soon after the second SRS. The post-second SRS MST of this subset was 3.1 months (IQR 1.5-5.7 months). As shown in Tables 2 and 4, the crude incidence of local recurrence was $15.8 \%$, and the cumulative incidences were $11.2 \%, 14.9 \%, 15.6 \%, 16.5 \%$, and $17.0 \%$ at $12,24,36,48$, and 60 months, respectively, after the second SRS. As shown in Table 5, the multivariable analysis revealed that a maximum tumor volume of $10 \mathrm{~cm}^{3}$ or larger (HR 2.760; 95\% CI 1.073-8.036; p $=0.0346)$ and locally recurrent lesions that had been irradiated at the first SRS (HR 2.433; 95\% CI 1.318-4.445; $\mathrm{p}=0.0048$ ) were significantly unfavorable predictors for local control after the second SRS. The mean peripheral dose that was administered to the locally recurrent lesions was slightly lower than the dose administered to the newly appearing lesions, but this difference did reach statistical significance (20.2 Gy vs 22.4 Gy; p < 0.0001).

Regarding post-second SRS salvage treatment, WBRT was performed in $28(3.3 \%)$ patients, surgical intervention was performed on $16(1.9 \%)$ patients, and a third SRS was performed in $281(32.7 \%)$ patients. The cumulative incidences of performing the third SRS procedures were $27.7 \%, 32.8 \%, 33.6 \%, 34.0 \%$, and $34.0 \%$ at $12,24,36,48$, and 60 months, respectively, after the second SRS.

SRS-induced complications occurred in 25 patients (2.9\%), with a median post-second SRS period of 16.8 months (range 0.6-95.0 months; IQR 5.6-29.3 months) and $4,1,13,7$, and 0 months for patients with RTOG Grades $0,1,2,3$, and 4, respectively. The cumulative incidences of complications were $1.4 \%, 2.0 \%, 2.4 \%, 3.0 \%$, and $3.0 \%$ at $12,24,36,48$ and 60 months, respectively, after the second SRS. The most common symptom was motor dysfunction (12 patients; $48.0 \%$ ), followed by visual field defect and decreased neurocognitive function in 2 patients each (8.0\% each) and balance disturbance, oculomotor nerve disturbance, and facial nerve paresis in 1 patient each (4.0\% each). Univariable analysis revealed no significant predictive factors. According to the univariable analyses, none of the pre-second SRS clinical factors and radiosurgical parameters were related to a higher incidences of complications.

\section{Discussion}

This study was retrospective. However, based on the

TABLE 4. Cumulative incidences of various treatment results after the second SRS*

\begin{tabular}{|c|c|c|c|c|c|}
\hline \multirow[b]{2}{*}{ Variable } & \multicolumn{5}{|c|}{ Cumulative Incidences } \\
\hline & $\begin{array}{c}12 \\
\text { Mos }\end{array}$ & $\begin{array}{c}24 \\
\text { Mos }\end{array}$ & $\begin{array}{c}36 \\
\text { Mos }\end{array}$ & $\begin{array}{c}48 \\
\text { Mos }\end{array}$ & $\begin{array}{c}60 \\
\text { Mos }\end{array}$ \\
\hline Neurological deterioration & 0.045 & 0.058 & 0.067 & 0.072 & 0.075 \\
\hline Local recurrence† & 0.112 & 0.149 & 0.156 & 0.165 & 0.170 \\
\hline Repeat SRS & 0.277 & 0.328 & 0.336 & 0.340 & 0.340 \\
\hline SRS-related complications & 0.014 & 0.020 & 0.024 & 0.030 & 0.030 \\
\hline
\end{tabular}


TABLE 5. Univariable and multivariable analyses of local recurrence after the second SRS

\begin{tabular}{|c|c|c|c|c|}
\hline \multirow[b]{2}{*}{ Variable } & \multicolumn{2}{|c|}{ Univariable } & \multicolumn{2}{|c|}{ Multivariable } \\
\hline & $\mathrm{HR}(95 \% \mathrm{Cl})$ & $p$ Value & $\mathrm{HR}(95 \% \mathrm{Cl})$ & $p$ Value \\
\hline \multicolumn{5}{|l|}{ Age, yrs } \\
\hline$\geq 65$ vs $<65$ & $1.366(0.898-2.104)$ & 0.1462 & & \\
\hline \multicolumn{5}{|l|}{ Sex } \\
\hline Male vs female & $1.205(0.796-1.829)$ & 0.3773 & & \\
\hline \multicolumn{5}{|l|}{ KPS } \\
\hline$<80 \%$ vs $\geq 80 \%$ & $2.261(1.047-4.321)$ & 0.0390 & $1.999(0.912-3.897)$ & 0.0804 \\
\hline \multicolumn{5}{|l|}{ M-RPA } \\
\hline $1+2 a$ vs $2 b$ & $1.323(0.814-2.188)$ & 0.2608 & & \\
\hline $2 c+3$ vs $2 b$ & $1.600(0.881-2.862)$ & 0.1209 & & \\
\hline \multicolumn{5}{|l|}{ Original tumor sites } \\
\hline Non-lung vs lung & $1.545(1.013-2.340)$ & 0.0437 & $1.294(0.830-1.997)$ & 0.2526 \\
\hline \multicolumn{5}{|l|}{ No. of lesions } \\
\hline $1 \mathrm{vs} \geq 2$ & $1.284(0.830-1.961)$ & 0.2568 & & \\
\hline$\leq 4$ vs $\geq 5$ & $1.326(0.842-2.162)$ & 0.2287 & & \\
\hline \multicolumn{5}{|l|}{ Tumor volume, $\mathrm{cm}^{3}$} \\
\hline Cumulative: $\geq 10$ vs $<10$ & $4.550(2.762-7.233)$ & $<0.0001$ & $1.220(0.452-2.771)$ & 0.6685 \\
\hline Largest tumor: $\geq 10$ vs $<10$ & $6.671(3.763-11.197)$ & $<0.0001$ & $2.760(1.073-8.036)$ & 0.0346 \\
\hline \multicolumn{5}{|l|}{ Type of recurrence } \\
\hline Local vs remote & $4.951(3.031-7.902)$ & $<0.0001$ & $2.433(1.318-4.445)$ & 0.0048 \\
\hline Both vs remote & $3.643(1.967-6.364)$ & 0.0001 & $2.986(1.570-5.368)$ & 0.0013 \\
\hline \multicolumn{5}{|l|}{ Minimum dose, Gy } \\
\hline$<24$ vs $\geq 24$ & $2.821(1.863-4.289)$ & $<0.0001$ & $1.511(0.907-2.496)$ & 0.1121 \\
\hline
\end{tabular}

relatively large sample size and the application of adequate statistical methods-i.e., competing risk analyses for secondary end points - this is the first analysis to demonstrate the importance of second SRS for patients with new postfirst SRS or recurrent brain metastases. As mentioned previously, several retrospective studies, which were based on relatively small patient numbers, have documented re-SRS to be safe and effective. ${ }^{7,20,32,47}$ Those studies considered overall survival, neurological death, tumor control, and/or SRS-induced complications with no maintenance of the neurological condition being described. Maintenance of good neurological function and, eventually, a decreased incidence of neurological death, have recently been recognized as being crucial for managing patients with brain metastases. We consider our herein-reported data set, with a relatively large sample size, to show that second SRS has the potential to achieve prolonged maintenance of neurological function and minimize neurological death based on the results that are essentially the same as those obtained with first SRS (Fig. 1B; Table 2). To summarize, the crude incidence of neurological death after the second SRS $(14.5 \%)$ was slightly higher than that after the first SRS (11.2\%), while the crude incidence of neurological deterioration after the second SRS (7.1\%) was slightly lower than that after the first SRS (12.1\%) (Table 2). However, these differences were negligible. Kwon et al. and Shuto et al. reported neurological death rates after the second SRS as $42.4 \%$ and $33.3 \%$, respectively-i.e., much higher than our present value of $14.5 \% .^{20,32}$ There were large differences in some of the baseline clinical characteristics between
Kwon et al.'s and our series: $67 \%$ of all patients had undergone WBRT and 36\% underwent re-SRS for recurrent tumors in Kwon et al.'s series, while 9.7\% of our patients received re-SRS and WBRT was an exclusion criterion in the present study.

\section{Overall Survival}

The reported post-second SRS MSTs - 7 to 8 monthsare consistent with our result of 7.4 months. ${ }^{7,20}$ Kwon et al. reported actuarial survival rates to be $57.6 \%$ and $28.0 \%$ at 6 and 12 months after the second SRS, respectively, ${ }^{20}$ which again is essentially the same as our results: $58.4 \%$ and $34.8 \%$, respectively. Furthermore, as shown in Fig. 1A, the post-second SRS MST and actuarial survival rates were almost the same as those after the first SRS. In our previously published study, good prognostic factors after the first SRS were KPS score $90 \%$ or greater, single brain metastasis, controlled primary tumor, and no extracranial metastasis. ${ }^{44}$ Also, we recently reported these results to be consistent even with those obtained after the second SRS. ${ }^{42}$ Shuto et al. reported that good prognostic factors after repeat SRS include a tumor number of 15 or less. ${ }^{32}$ In our study, female sex, KPS score $80 \%$ or better, better MRPA class, a smaller number of tumors, and a peripheral dose of 24 Gy or higher were found to be good prognostic factors after the second SRS (Table 3).

\section{Local Control}

In this study, the local control rate after the second 
SRS-15.8\% - is not unsatisfactory and was actually higher than that after the first SRS (8.0\%) (Table 2). Kwon et al. reported an actuarial local recurrence-free rate of $90.7 \%$ at 6 months after the second SRS. ${ }^{20}$ Nevertheless, they used the original Kaplan-Meier method, which is not considered to be optimal for modern medical statistics. In this study, the cumulative incidence was determined by competing risk analysis to be $11.2 \%$ at 12 months after the second SRS (Table 4). Woo et al. reported the absence of a rapid fall-off radiation dose around a lesion to be an unfavorable factor for local recurrence. ${ }^{39}$ Furthermore, the type of primary cancer was also reported to be related to local control., ${ }^{9,34}$ Our present results indicate remote recurrence (vs local recurrence) and maximum tumor volume less than $10 \mathrm{~cm}^{3}$ to be factors that favor good local control. Regarding this difference-i.e., remote versus local recurrence - a relatively high incidence of local recurrence probably stems from relatively low doses at the time of the second SRS.

\section{Complications}

Debate continues as to whether multiple SRS procedures correlate with a higher incidence of complications. Shuto et al. reported the rate of radiation-induced injury to be $9.2 \%$ in patients undergoing SRS more than 4 times. ${ }^{32}$ However, in our previous study based on 167 patients who survived over 3 years after the first SRS, univariable analyses failed to show that numbers of SRS procedures, as either a continuous or a categorical variable, correlated with a higher incidence of SRS-induced complications. ${ }^{41}$ As shown in Table 2, the crude incidence of post-second SRS complications $(2.9 \%)$ was almost the same as that after the first SRS (2.8\%). Also, as shown in Table 4, the cumulative incidences of post-second SRS complications, which were determined using a competing risk analysis, were low compared with those of the JLGK0901 Study: $6 \%$ to $8 \%, 10 \%$ to $11 \%, 11 \%$ to $12 \%, 12 \%$ to $13 \%$, and $12 \%$ to $14 \%$ at $1,2,3,4$, and 5 years after the first SRS. ${ }^{46}$

\section{Patient Selection for the Second SRS}

The second SRS protocol is mostly performed in patients with new lesions. As mentioned previously, no special considerations are necessary for new brain metastases that develop after the first SRS; i.e., the approach should be similar to that used for patients with an initially diagnosed brain metastasis. Nevertheless, performing the second SRS is not urgent if the diameter of the largest lesion is less than $1 \mathrm{~cm}$. In fact, meticulous follow-up MRI is recommended until the diameter of a new lesion exceeds $1 \mathrm{~cm}$. If small lesions are detected by follow-up post-SRS MRI, some tumors will grow slowly while others will be controlled, or possibly even disappear, in response to systemic chemotherapy or targeted therapy. In such cases, reSRS can be postponed. Also, among such patients, there will be a subset whose general conditions deteriorate remarkably due to systemic cancer progression before the brain lesions increase in size to exceed $1 \mathrm{~cm}$ in diameter. In such cases, re-SRS offers no benefits. However, if new lesions are located near critical or eloquent areas, like the brainstem, optic apparatus, or motor area, the second SRS should be performed without further observation even if the maximum lesion diameter is 2 to $3 \mathrm{~mm}$.

In contrast, the second SRS should not be delayed for patients with recurrent lesions. However, differentiation of tumor recurrence from necrotic changes is difficult in some cases based on MR imaging alone. ${ }^{17,19}$ In such cases, perfusion-weighted MRI, 2,14,24,36 MR spectroscopy, ${ }^{201} \mathrm{Tl}$ SPECT, ${ }^{31}$ and PET using 2-deoxy-[$\left.{ }^{18} \mathrm{~F}\right]$ fluoro-D-glu$\operatorname{cose}^{3,6,8}$ have been used, though none of these examinations has sufficient diagnostic certainty. Therefore, we recommend using ${ }^{11} \mathrm{C}$-methionine PET because its sensitivity and specificity are far greater than with the aforementioned methods. ${ }^{25,26,37}$

For patients with new and/or recurrent lesions, a prognostic grading index needs to be developed for re-SRS. Five indices-recursive partitioning analysis, ${ }^{10}$ Score Index for Radiosurgery, ${ }^{38}$ Basic Score for Brain Metastases, ${ }^{21}$ Graded Prognostic Assessment, ${ }^{33}$ and M-RPA ${ }^{40,44,45}$-were proposed for patients with initially diagnosed brain metastases. As we reported elsewhere, our M-RPA system was shown to be the most applicable to patients receiving reSRS in terms of the proportions of patients in the 3 M-RPA subclasses and MST separation among the 3 groups and to better reflect patient status changes as well as post-re-SRS MSTs.

\section{Limitations of This Study}

This was a retrospective study, and as such the major limitation would be the obvious heterogeneity of the clinical factors. Second, there were considerable biases in patient selection, as well as in post-first and post-second SRS observations. Also, meticulous follow-up imaging was lacking in approximately $25 \%$ of our cohort because most of these patients deteriorated or died rather early due to systemic disease progression before post-second SRS imaging examinations could be performed. Third, data on systemic chemotherapy or targeted therapy, which are considered to be very important for discussing overall survival, tumor control, new lesion appearance, etc., are lacking in the present study because our prospectively accumulated database does not include such information. Immunomodulatory agent therapy is not as yet covered by the Japanese National Insurance System and, therefore, has been administered only to very limited numbers of patients (e.g., patients participating in clinical trials).

\section{Conclusions}

We conclude that carefully selected patients with recurrent tumors, either new or locally recurrent, are favorable candidates for second SRS. In other words, post-second SRS results-not only overall survival but also other secondary end points - were not inferior to those after the first SRS. In particular, maintenance of a good neurological condition can be expected even at 5 years after the second SRS in over $90 \%$ of patients.

\section{Acknowledgments}

We are very grateful to Bierta E. Barfod, MD-who has more than 25 years of experience in proofreading English medical articles 
and presently works at Katsuta Hospital Mito GammaHouse-for her help with English-language editing.

\section{References}

1. Aoyama H, Tago M, Kato N, Toyoda T, Kenjyo M, Hirota $S$, et al: Neurocognitive function of patients with brain metastasis who received either whole brain radiotherapy plus stereotactic radiosurgery or radiosurgery alone. Int J Radiat Oncol Biol Phys 68:1388-1395, 2007

2. Barajas RF, Chang JS, Sneed PK, Segal MR, McDermott MW, Cha S: Distinguishing recurrent intra-axial metastatic tumor from radiation necrosis following Gamma Knife radiosurgery using dynamic susceptibility-weighted contrastenhanced perfusion MR imaging. AJNR Am J Neuroradiol 30:367-372, 2009

3. Belohlávek O, Simonová G, Kantorová I, Novotný J Jr, Liscák R: Brain metastases after stereotactic radiosurgery using the Leksell Gamma Knife: can FDG PET help to differentiate radionecrosis from tumour progression? Eur J Nucl Med Mol Imaging 30:96-100, 2003

4. Bindal RK, Sawaya R, Leavens ME, Lee JJ: Surgical treatment of multiple brain metastases. J Neurosurg 79:210-216, 1993

5. Chang EL, Wefel JS, Hess KR, Allen PK, Lang FF, Kornguth DG, et al: Neurocognition in patients with brain metastases treated with radiosurgery or radiosurgery plus whole-brain irradiation: a randomised controlled trial. Lancet Oncol 10:1037-1044, 2009

6. Chao ST, Ahluwalia MS, Barnett GH, Stevens GH, Murphy ES, Stockham AL, et al: Challenges with the diagnosis and treatment of cerebral radiation necrosis. Int J Radiat Oncol Biol Phys 87:449-457, 2013

7. Chen JC, Petrovich Z, Giannotta SL, Yu C, Apuzzo ML: Radiosurgical salvage therapy for patients presenting with recurrence of metastatic disease to the brain. Neurosurgery 46:860-867, 2000

8. Chernov M, Hayashi M, Izawa M, Ochiai T, Usukura M, Abe $\mathrm{K}$, et al: Differentiation of the radiation-induced necrosis and tumor recurrence after gamma knife radiosurgery for brain metastases: importance of multi-voxel proton MRS. Minim Invasive Neurosurg 48:228-234, 2005

9. Flickinger JC, Kondziolka D, Lunsford LD, Coffey RJ, Goodman ML, Shaw EG, et al: A multi-institutional experience with stereotactic radiosurgery for solitary brain metastasis. Int J Radiat Oncol Biol Phys 28:797-802, 1994

10. Gaspar L, Scott C, Rotman M, Asbell S, Phillips T, Wasserman T, et al: Recursive partitioning analysis (RPA) of prognostic factors in three Radiation Therapy Oncology Group (RTOG) brain metastases trials. Int J Radiat Oncol Biol Phys 37:745-751, 1997

11. Hanssens P, Karlsson B, Yeo TT, Chou N, Beute G: Detection of brain micrometastases by high-resolution stereotactic magnetic resonance imaging and its impact on the timing of and risk for distant recurrences. J Neurosurg 115:499-504, 2011

12. Hazuka MB, Kinzie JJ: Brain metastases: results and effects of re-irradiation. Int J Radiat Oncol Biol Phys 15:433-437, 1988

13. Hochstenbag MM, Twijnstra A, Hofman P, Wouters EF, ten Velde GP: MR-imaging of the brain of neurologic asymptomatic patients with large cell or adenocarcinoma of the lung. Does it influence prognosis and treatment? Lung Cancer 42:189-193, 2003

14. Hoefnagels FW, Lagerwaard FJ, Sanchez E, Haasbeek CJ, Knol DL, Slotman BJ, et al: Radiological progression of cerebral metastases after radiosurgery: assessment of perfusion MRI for differentiating between necrosis and recurrence. J Neurol 256:878-887, 2009
15. Kano H, Kondziolka D, Lobato-Polo J, Zorro O, Flickinger JC, Lunsford LD: T1/T2 matching to differentiate tumor growth from radiation effects after stereotactic radiosurgery. Neurosurgery 66:486-492, 2010

16. Karlsson B, Hanssens P, Wolff R, Söderman M, Lindquist C, Beute G: Thirty years' experience with Gamma Knife surgery for metastases to the brain. J Neurosurg 111:449-457, 2009

17. Kickingereder P, Dorn F, Blau T, Schmidt M, Kocher M, Galldiks N, et al: Differentiation of local tumor recurrence from radiation-induced changes after stereotactic radiosurgery for treatment of brain metastasis: case report and review of the literature. Radiat Oncol 8:52-59, 2013

18. Kim SY, Kim JS, Park HS, Cho MJ, Kim JO, Kim JW, et al: Screening of brain metastasis with limited magnetic resonance imaging (MRI): clinical implications of using limited brain MRI during initial staging for non-small cell lung cancer patients. J Korean Med Sci 20:121-126, 2005

19. Kimura T, Sako K, Tanaka K, Gotoh T, Yoshida H, Aburano $\mathrm{T}$, et al: Evaluation of the response of metastatic brain tumors to stereotactic radiosurgery by proton magnetic resonance spectroscopy, ${ }^{201} \mathrm{TlCl}$ single-photon emission computerized tomography, and gadolinium-enhanced magnetic resonance imaging. J Neurosurg 100:835-841, 2004

20. Kwon KY, Kong DS, Lee JI, Nam DH, Park K, Kim JH: Outcome of repeated radiosurgery for recurrent metastatic brain tumors. Clin Neurol Neurosurg 109:132-137, 2007

21. Lorenzoni J, Devriendt D, Massager N, David P, Ruíz S, Vanderlinden B, et al: Radiosurgery for treatment of brain metastases: estimation of patient eligibility using three stratification systems. Int J Radiat Oncol Biol Phys 60:218-224, 2004

22. Matsuo M, Miwa K, Shinoda J, Kako N, Nishibori H, Sakurai $\mathrm{K}$, et al: Target definition by C11-methionine-PET for the radiotherapy of brain metastases. Int J Radiat Oncol Biol Phys 74:714-722, 2009

23. Mehta MP, Rozental JM, Levin AB, Mackie TR, Kubsad SS, Gehring MA, et al: Defining the role of radiosurgery in the management of brain metastases. Int J Radiat Oncol Biol Phys 24:619-625, 1992

24. Mitsuya K, Nakasu Y, Horiguchi S, Harada H, Nishimura T, Bando E, et al: Perfusion weighted magnetic resonance imaging to distinguish the recurrence of metastatic brain tumors from radiation necrosis after stereotactic radiosurgery. $\mathbf{J}$ Neurooncol 99:81-88, 2010

25. Momose T, Nariai T, Kawabe T, Inaji M, Tanaka Y, Watanabe $\mathrm{S}$, et al: Clinical benefit of ${ }^{11} \mathrm{C}$ methionine PET imaging as a planning modality for radiosurgery of previously irradiated recurrent brain metastases. Clin Nucl Med 39:939-943, 2014

26. Nariai T, Tanaka Y, Wakimoto H, Aoyagi M, Tamaki M, Ishiwata $\mathrm{K}$, et al: Usefulness of $\mathrm{L}-\left[\right.$ methyl $\left.-{ }^{11} \mathrm{C}\right]$ methioninepositron emission tomography as a biological monitoring tool in the treatment of glioma. J Neurosurg 103:498-507, 2005

27. Noordijk EM, Vecht CJ, Haaxma-Reiche H, Padberg GW, Voormolen JH, Hoekstra FH, et al: The choice of treatment of single brain metastasis should be based on extracranial tumor activity and age. Int J Radiat Oncol Biol Phys 29:711-717, 1994

28. Patchell RA, Tibbs PA, Walsh JW, Dempsey RJ, Maruyama $\mathrm{Y}$, Kryscio RJ, et al: A randomized trial of surgery in the treatment of single metastases to the brain. N Engl J Med 322:494-500, 1990

29. Radiation Therapy Oncology Group: Cooperative Group Common Toxicity Criteria. (https://www.rtog.org/ResearchAssociates/AdverseEventReporting/CooperativeGroupCommonToxicityCriteria.aspx) [Accessed July 8, 2016]

30. Serizawa T, Hirai T, Nagano O, Higuchi Y, Matsuda S, Ono J, et al: Gamma Knife surgery for 1-10 brain metastases without prophylactic whole-brain radiation therapy: analysis of 
cases meeting the Japanese prospective multi-institute study (JLGK0901) inclusion criteria. J Neurooncol 98:163-167, 2010

31. Serizawa T, Saeki N, Higuchi Y, Ono J, Matsuda S, Sato M, et al: Diagnostic value of thallium-201 chloride singlephoton emission computerized tomography in differentiating tumor recurrence from radiation injury after Gamma Knife surgery for metastatic brain tumors. J Neurosurg 102 Suppl:266-271, 2005

32. Shuto T, Fujino H, Inomori S, Nagano H: Repeated Gamma Knife radiosurgery for multiple metastatic brain tumours. Acta Neurochir (Wien) 146:989-993, 2004

33. Sperduto PW, Berkey B, Gaspar LE, Mehta M, Curran W: A new prognostic index and comparison to three other indices for patients with brain metastases: an analysis of 1,960 patients in the RTOG database. Int J Radiat Oncol Biol Phys 70:510-514, 2008

34. Sperduto PW, Chao ST, Sneed PK, Luo X, Suh J, Roberge $\mathrm{D}$, et al: Diagnosis-specific prognostic factors, indexes, and treatment outcomes for patients with newly diagnosed brain metastases: a multi-institutional analysis of 4,259 patients.

Int J Radiat Oncol Biol Phys 77:655-661, 2010

35. Sturm V, Kober B, Höver KH, Schlegel W, Boesecke R, Pastyr O, et al: Stereotactic percutaneous single dose irradiation of brain metastases with a linear accelerator. Int J Radiat Oncol Biol Phys 13:279-282, 1987

36. Truong MT, St Clair EG, Donahue BR, Rush SC, Miller DC, Formenti SC, et al: Results of surgical resection for progression of brain metastases previously treated by Gamma Knife radiosurgery. Neurosurgery 59:86-97, 2006

37. Tsuyuguchi N, Sunada I, Iwai Y, Yamanaka K, Tanaka K, Takami T, et al: Methionine positron emission tomography of recurrent metastatic brain tumor and radiation necrosis after stereotactic radiosurgery: is a differential diagnosis possible? J Neurosurg 98:1056-1064, 2003

38. Weltman E, Salvajoli JV, Brandt RA, de Morais Hanriot R, Prisco FE, Cruz JC, et al: Radiosurgery for brain metastases: a score index for predicting prognosis. Int J Radiat Oncol Biol Phys 46:1155-1161, 2000

39. Woo HJ, Hwang SK, Park SH, Hwang JH, Hamm IS: Factors related to the local treatment failure of Gamma Knife surgery for metastatic brain tumors. Acta Neurochir (Wien) 152:1909-1914, 2010

40. Yamamoto M, Kawabe T, Higuchi Y, Sato Y, Barfod BE, Kasuya $\mathrm{H}$, et al: Validity of three recently proposed prognostic grading indexes for breast cancer patients with radiosurgically treated brain metastases. Int J Radiat Oncol Biol Phys 84:1110-1115, 2012

41. Yamamoto M, Kawabe T, Higuchi Y, Sato Y, Nariai T, Barfod BE, et al: Delayed complications in patients surviving at least 3 years after stereotactic radiosurgery for brain metastases. Int J Radiat Oncol Biol Phys 85:53-60, 2013

42. Yamamoto M, Kawabe T, Higuchi Y, Sato Y, Nariai T, Watanabe $\mathrm{S}$, et al: Validity of prognostic grading indices for brain metastasis patients undergoing repeat radiosurgery. World Neurosurg 82:1242-1249, 2014

43. Yamamoto M, Kawabe T, Sato Y, Higuchi Y, Nariai T, Bar- fod BE, et al: A case-matched study of stereotactic radiosurgery for patients with multiple brain metastases: comparing treatment results for 1-4 vs $\geq 5$ tumors: clinical article. J Neurosurg 118:1258-1268, 2013

44. Yamamoto M, Sato Y, Serizawa T, Kawabe T, Higuchi Y, Nagano O, et al: Subclassification of recursive partitioning analysis Class II patients with brain metastases treated radiosurgically. Int J Radiat Oncol Biol Phys 83:1399-1405, 2012

45. Yamamoto M, Serizawa T, Sato Y, Kawabe T, Higuchi Y, Nagano O, et al: Validity of two recently-proposed prognostic grading indices for lung, gastro-intestinal, breast and renal cell cancer patients with radiosurgically-treated brain metastases. J Neurooncol 111:327-335, 2013

46. Yamamoto M, Serizawa T, Shuto T, Akabane A, Higuchi Y, Kawagishi J, et al: Stereotactic radiosurgery for patients with multiple brain metastases (JLGK0901): a multi-institutional prospective observational study. Lancet Oncol 15:387-395, 2014

47. Yamanaka K, Iwai Y, Yasui T, Nakajima H, Komiyama M, Nishikawa M, et al: Gamma Knife radiosurgery for metastatic brain tumor: the usefulness of repeated Gamma Knife radiosurgery for recurrent cases. Stereotact Funct Neurosurg 72 (Suppl 1):73-80, 1999

\section{Disclosures}

The authors report no conflict of interest concerning the materials or methods used in this study or the findings specified in this paper.

\section{Author Contributions}

Conception and design: M Yamamoto. Acquisition of data: M Yamamoto, Kawabe, Watanabe. Analysis and interpretation of data: M Yamamoto, Koiso, Kawabe. Drafting the article: Koiso. Critically revising the article: M Yamamoto, T Yamamoto, Matsumura, Kasuya. Reviewed submitted version of manuscript: $M$ Yamamoto, Koiso, Kawabe, Watanabe, T Yamamoto, Matsumura, Kasuya. Approved the final version of the manuscript on behalf of all authors: M Yamamoto. Statistical analysis: Sato, Higuchi. Study supervision: M Yamamoto, T Yamamoto, Matsumura, Kasuya.

\section{Supplemental Information Previous Presentations}

Portions of this work were presented in an oral form on October 14, 2015, at the 74th Annual Meeting of the Japan Neurosurgical Society, Sapporo, Japan.

\section{Correspondence}

Masaaki Yamamoto, Katsuta Hospital, Mito GammaHouse, Nakane 5125-2, Hitachinaka, Ibaraki 312-0011, Japan. email: bcd06275@nifty.com. 